\title{
Left ventricular thickness may be affected by higher arterial blood pressure and body-mass index in asymptomatic adolescents
}

\author{
Arbnora Batalli-Kipuska*, Arlind Batalli, Gani Bajraktari \\ University Clinical Center of Kosova, Prishtina, Republic of Kosovo
}

Background and Aim: Structural and functional cardiac changes are known in obese adults but respective disturbances in children and adolescents are still controversial. The aim of this study was to assess the relationship between arterial blood pressure, body mass index (BMI) and echocardiagraphic measurements in overweight and obese asymptomatic adolescents

Methods: This study included 93 healthy subjects aged 1015 years (mean $12.6 \pm 1.2$ years). In all, systolic and diastolic blood pressure, weight, height, BMI, waist, hips, waist/hips ratio, hematologic and biochemical blood tests were assessed. Based on BMI, subjects were divided into three groups: lean $(L, n=32)$, overweight $(O v, n=33)$ and obese $(O b$, $\mathrm{n}=32$ ). On the same day, a complete transthoracic echocardiographic examination was performed.

Results: Interventricular septal and LV posterior wall enddiastolic thickness was increased parallel to the BMI (L: 0.84 $\pm 0.09 \mathrm{~cm}, \mathrm{Ov}: 0.88 \pm 0.1 \mathrm{~cm}, \mathrm{Ob}: 0.96 \pm 0.1 \mathrm{~cm}, p<0.001$, and L: $0.78 \pm 0.1 \mathrm{~cm}, \mathrm{Ov}: 0.80 \pm 0.09 \mathrm{~cm}, \mathrm{Ob}: 0.94 \pm 0.08 \mathrm{~cm}$, $p<0.001$, respectively). Relative wall thickness (RWT) and LV mass index (LVMI) adjusted to body surface area were similarly increased (L: $0.34 \pm 0.05, \mathrm{Ov}: 0.34 \pm 0.05, \mathrm{Ob}: 0.40$ $\pm 0.04, p<0.001$, and $L: 78 \pm 13 \mathrm{~g} / \mathrm{m}^{2}, \mathrm{Ov}: 77.6 \pm 13 \mathrm{~g} / \mathrm{m}^{2}, \mathrm{Ob}$ : $86.9 \pm 16.3 \mathrm{~g} / \mathrm{m}^{2}, \mathrm{p}=0.022$, respectively). Systolic blood pressure $(\mathrm{SBP})$ values were significantly different (L: $107.5 \pm 7.5$
mmHg, Ov: $115 \pm 11 \mathrm{mmHg}, \mathrm{Ob}: 118 \pm 12 \mathrm{mmHg}, \mathrm{p}<0.001)$, whereas diastolic blood pressure (DBP) values were not significant (L: $74 \pm 6 \mathrm{mmHg}, \mathrm{Ov}: 76 \pm 7 \mathrm{mmHg}, \mathrm{Ob}: 74 \pm 9$ $\mathrm{mmHg}, \mathrm{p}=0.428$ ) between groups. SBP correlated with BMI $(r=0.282, p=0.006)$ and with LV posterior wall thickness $(r=0.243, p=0.019)$, whereas DBP correlate with LV ejection fraction ( $r=-0.227, p=0.029)$, with deceleration time of $E$ wave $(r=-0.223, p=0.032)$, with LV lateral early diastolic velocity $(r=0.215, p=0.039)$.

Conclusions: The systolic blood pressure is higher in obese and overweight adolescent compared with lean adolescents. Both, high blood pressure and obesity, may affect the left ventricular systolic and diastolic function in these patients.

KEYWORDS: adolescents, blood pressure, body mass index, hypertension, echocardiography.

\section{Received: $20^{\text {th }}$ Mar 2013}

*Address for correspondence: Pediatric Cardiology, University Clinical Center, 10000 Priština, Kosovo.

Phone: +37744207268

E-mail: drnorakep@ hotmail.com

\section{Literature}

1. Archenti A, Pasqualinotto L. Childhood obesity: the epidemic of the third millenium. Acta Biomed. 2008;79:151-5.

2. Cali AM, Caprio S. Obesity in children and adolescents. J Clin Endocrinol Metab. 2008;93:S31-S36.

3. Ogden CL, Carroll MD, Flegal KM. High body mass index for age among US children and adolescents, 2003-2006. JAMA. 2008;299:2401-5.

4. Hammond IW, Devereux RB, Alderman MH, Laragh JH. Relation of blood pressure and body build to left ventricular mass in normotensive and hypertensive employed adults. $\mathrm{J}$ Am Coll Cardiol. 1988;12:996-1004.

5. Messerli FH, Sundgaard-Riise K, Reisin ED, et al. Dimorphic cardiac adaptation to obesity and arterial hypertension. Ann Intern Med. 1983;99:757-61.

6. Alpert MA, Lambert CR, Terry BE, et al. Influence of left ventricular mass on left ventricular diastolic filling in normotensive morbid obesity. Am Heart J. 1995;130:1068-73. 